\title{
The association between symptoms of depression during pregnancy and low birth weight: a prospective study
}

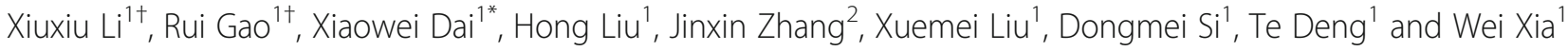

\begin{abstract}
Background: Most studies have showed that maternal depression is associated with pregnancy complications. However, there were limited evidences in Chinese population. We examined the associations of antenatal depression symptoms with pregnancy outcomes, especially for low birth weight.

Methods: A total of 1377 singleton pregnant women were recruited from Nanshan Maternity \& Child Healthcare Hospital of Shenzhen in this prospective cohort study. Depression symptoms were assessed by the Edinburgh postnatal depression scale (EPDS) questionnaire in the second trimester of gestation; cut-points for the indication of antenatal depression were $\geqq 12$ scores in this study. Socio-demographic data, life-style and pregnancy outcomes were collected through Shenzhen Maternity \& Child Healthcare database. The risks of adverse outcomes in pregnant women with antenatal depression were determined by multivariate logistic regression and represented as odds ratio(OR) and 95\% confidence interval (Cl).

Results: Of the 1377 subjects, the prevalence of antenatal depression was $19.1 \%$. The EPDS scores were $13.8 \pm 2.0$ and $6.5 \pm 2.9(P<0.001)$ in subjects with and without antenatal depression, respectively. After adjustment for maternal age, education, parity, pre-pregnancy body mass index (BMI), residential area, fetal gender, an EPDS score $\geq 12$ (versus. <12) was associated with an increased risk for low birth weight (odds ratio: 2.05, 95\% Cl: 1.124.64), but not for preterm birth, large for gestational age, small for gestational age or macrosomia.

Conclusion: Pregnant women presenting antenatal depressive symptoms are at elevated risk of low birth weight. Mental health problems of pregnancy should be addressed for the prevention of low birth weight.
\end{abstract}

Keywords: Antenatal depression, Low birth weight, Preterm birth, Small for gestational age

\section{Background}

According to the World Health Organization (WHO) [1], depression is one of the main factors for the increase of women disability adjusted life years worldwide. Depression during pregnancy is quite common, with up to $30 \%$ of pregnant women experiencing significant depressive symptoms [2, 3]. A systematic review of 28 observational

\footnotetext{
* Correspondence: dxwpc2004@126.com

${ }^{\dagger}$ Xiuxiu Li and Rui Gao contributed equally to this work.

${ }^{1}$ Nanshan Maternity \& Child Healthcare Hospital of Shenzhen, Shenzhen, China

Full list of author information is available at the end of the article
}

studies (including cross-sectional, cohort, and casecontrol studies) have estimated that the prevalence of major depression in pregnancy was $3.1-4.9 \%$ and that of mild depression was $11 \%$ in high-income countries [4]. In low and middle-income countries, the incidence rate of either major or mild depression is more severe [5]. The prevalence of depression in pregnancy reported in China varied between 3.8 and $35.9 \%$ due to different screening tools [6-8]. However, diagnosis of depression in pregnant women might be underestimated due to the antenatal hormone levels, and low willingness to participate in such

(c) The Author(s). 2020 Open Access This article is licensed under a Creative Commons Attribution 4.0 International License, which permits use, sharing, adaptation, distribution and reproduction in any medium or format, as long as you give appropriate credit to the original author(s) and the source, provide a link to the Creative Commons licence, and indicate if changes were made. The images or other third party material in this article are included in the article's Creative Commons licence, unless indicated otherwise in a credit line to the material. If material is not included in the article's Creative Commons licence and your intended use is not permitted by statutory regulation or exceeds the permitted use, you will need to obtain permission directly from the copyright holder. To view a copy of this licence, visit http://creativecommons.org/licenses/by/4.0/ The Creative Commons Public Domain Dedication waiver (http://creativecommons.org/publicdomain/zero/1.0/) applies to the data made available in this article, unless otherwise stated in a credit line to the data. 
studies for those pregnant women with depression [6]. Therefore, more research on the effective screening or diagnosis of antenatal depression in Chinese pregnant women are warranted.

Depression associated with pregnancy not only damages the physical and mental health of the pregnant woman, but also has an important impact on the future psychological and intellectual development of the fetus [7, 8]. A number of studies have evaluated the impact of depressive symptoms on low birth weight (LBW), which is associated with increased risk of infant mortality and morbidity [9]. However, the results were inconsistent and varied by sample size and the methods used to measure depression [10]. Nonetheless, most of these studies were conducted in high-income countries. Considering the high-speed development of economy and lifestyle transition in China and the potential for ethnic variations, it is important to determine whether antenatal depression is associated with the risk of LBW in the Chinese population. Shenzhen is the city with largest floating population in China, in which pregnant women may experience more pressure, and thus bring more serious mental health problems. This study aims to investigate whether the antenatal depression symptoms is a risk factor for adverse birth outcomes in a Chinese population.

\section{Methods}

\section{Participants}

Participants were recruited from the antenatal clinic in the Shenzhen Nanshan Maternity \& Child Healthcare Hospital in China between October 2015 and April 2017. Exclusion criteria were serious disease before pregnancy (eg, hypertensive disorders, diabetes) or obstetric complications (eg, incompetent cervix, fetal abnormality, non-singleton pregnancies). A total of 1500 subjects were enrolled in the present study. Then data on socio-demographic information were collected by interview, and depression symptoms were assessed by the Edinburgh postnatal depression scale (EPDS) questionnaire, in the second trimester. Data on birth outcomes were obtained from the database. Some participants without delivery information on database were contacted via telephone after delivery to obtain information pertaining to birth outcome. Finally, a total of 1377 women were included, and 123 subjects were excluded due to they were not available to be reached via telephone. This study was approved by the ethics committee of the Maternal \& Child Healthcare Hospital of Nanshan district in Shenzhen (NO. 2015NSFYEC010), and all participants provided written consent.

\section{Data collection}

\section{Demographic characteristics and obstetric conditions}

Information on demographic data such as age, occupation and type of household registration were collected by questionnaires. Information on maternal age, prepregnancy body mass index (calculated from reported height and weight), number of existing children, high risk pregnancy, smoking history (ever/never),passive smoking and data on alcohol use during pregnancy (yes/no) was recorded at first antenatal care visit. Maternal education was categorized into middle school, high school, college or University and post-graduated or graduate. High-risk pregnancy is defined as pregnancy in which the mother and/or fetus has higher mortality risk than generally healthy counterpart. Causes of high-risk pregnancy included inadequate prenatal care, previous obstetrical history (abortion and spontaneous), pre-existing maternal disease, pregnancy-induced disease (gestational hypertension), and advanced maternal age above 35 years [11].

\section{Exposure of depression}

Antenatal depression was evaluated during the second trimester using the Edinburgh Postnatal Depression Scale (EPDS) [12, 13]. The EPDS is a 10-item self-report questionnaire to measure the last 7 days of emotional expression. Each question has four options, with a range of 0-3 points. The maximum score is 30 and higher scores suggest more serious depressive symptoms. Although this scale was initially developed for use in a postnatal female population to measure the mood of women after delivery, the effectiveness in antenatal women has been verified by previous studies with excellent reliability [12, 14]. Furthermore, a Chinese translation of the EPDS has been demonstrated to have good reliability and validity, with an internal consistency (Cronbach's a) of 0.87 [15]. In this study, a cut-off score of 12 was used to identify women with depression [16].

\section{Outcomes}

Information on pregnancy outcomes was collected at Shenzhen Maternity \& Child Healthcare database, which includes antenatal and obstetric data from all pregnant women in Shenzhen city. Outcomes of interest were low birth weight, preterm birth, and small for gestational age. Birth data were obtained from hospital records. Low birth weight (LBW) was defined as birth weight less than $2500 \mathrm{~g}$, and preterm birth (PTB) was less than 37 weeks' gestation, small for gestational age (SGA) was that birth weight was lower than the 10th percentile of the average weight of the same gestational age [17].

\section{Statistical analyses}

Data were analyzed with SPSS 20.0 for Windows (SPSS Inc., Chicago, IL, USA), and two-sided $p$ values of less than 0.05 were considered to be statistically significant. Data were presented as means (and SD) for continuous variables or proportions (\%) for categorical variables. Participants were divided into two groups based on 
EPDS score: a non-depressed group (EPDS score $<12$ ), and a depressed group (EPDS score $\geq 12$ ). The participants' characteristics were compared by chi-square test or Student $t$ test among two groups. The association between depression symptoms and birth outcomes were obtained by chi-square test.

Multivariate logistic regression models were applied to estimate the odds ratios (95\% confidence interval) for the risk of low birth weight by comparing the EPDS score $\geqq 12$ and $<12$. Adjusted covariates were age, prepregnancy BMI, neonatal gender, degree of education, high-risk women and parity. Model1 was not adjusted by previous confounders. Model 2 was adjusted for potential confounding variables as above. The variables were entered into the models. A stratified analysis was performed to examine the association of depression symptoms and LBW at different levels of maternal age, residence type, pre-pregnancy BMI and newborn gender.

\section{Results}

Demographic characteristics information

We approached 1500 women to participate in the study. Questionnaires were all received while 123 women did not give birth in Shenzhen and we were not able to contact them. Therefore, this study reports on a sample of 1377 women (92\% of the enrolled sample) who had complete data available for analysis.

In our study, 256 women (19.3\%) had antenatal depression. Demographic characteristics of women with and without antenatal depression were compared (Table 1).

Women less than 25 years, were more likely to have antenatal depression than their counterparts $(P<0.05)$. A significant difference was found in the type of household residence among the two groups $(P<0.05)$. That is, Antenatal depression symptoms were more common among temporary residents than permanent residents

Table 1 Demographic characteristics of women with and without antenatal depression

\begin{tabular}{|c|c|c|c|c|c|}
\hline & \multicolumn{2}{|c|}{ Not depressed (EPDS< 12) } & \multicolumn{2}{|c|}{ Depressed (EPDS $\geq 12$ ) } & \multirow[t]{2}{*}{$P$} \\
\hline & Mean \pm SD or $\%$ & Number & Mean \pm SD or $\%$ & Number & \\
\hline EPDS score & $6.5 \pm 2.9$ & 1109 & $13.8 \pm 2.0$ & 265 & $<0.001$ \\
\hline \multicolumn{6}{|l|}{ Age, years } \\
\hline$<25$ & 4.3 & 48 & 7.8 & 21 & \multirow[t]{3}{*}{0.030} \\
\hline $25-34$ & 78.6 & 872 & 78.7 & 211 & \\
\hline$\geq 35$ & 17.0 & 189 & 13.4 & 36 & \\
\hline \multicolumn{6}{|l|}{ Education } \\
\hline Under and middle school & 3.2 & 36 & 3.7 & 10 & \multirow[t]{4}{*}{0.901} \\
\hline high school & 49.7 & 551 & 48.9 & 131 & \\
\hline College or University & 42.1 & 467 & 43.3 & 116 & \\
\hline Post-graduated and higher & 5.0 & 55 & 4.1 & 11 & \\
\hline \multicolumn{6}{|l|}{ Household registration type } \\
\hline Shenzhen residence & 39.0 & 432 & 30.6 & 82 & \multirow[t]{3}{*}{0.032} \\
\hline Temporary residence & 58.4 & 648 & 67.2 & 180 & \\
\hline Floating household & 2.6 & 29 & 2.2 & 6 & \\
\hline \multicolumn{6}{|l|}{ Pre-pregnancy BMI,(kg/m²) } \\
\hline$<18.5$ & 17.9 & 195 & 24.9 & 65 & \multirow[t]{4}{*}{0.076} \\
\hline $18.5-23.9$ & 69.5 & 756 & 63.2 & 165 & \\
\hline $24-27.9$ & 10.9 & 118 & 10.7 & 28 & \\
\hline$>28$ & 1.7 & 18 & 1.1 & 3 & \\
\hline Passive smoking, Yes & 26.0 & 288 & 28.0 & 75 & 0.773 \\
\hline \multicolumn{6}{|l|}{ Parity } \\
\hline Primigravida & 64.7 & 718 & 67.2 & 180 & \multirow[t]{2}{*}{0.455} \\
\hline Multigravida & 35.3 & 391 & 32.8 & 88 & \\
\hline High risk pregnancy, Yes & 49.1 & 544 & 52.2 & 140 & 0.349 \\
\hline
\end{tabular}


(67.2\% vs. $58.4 \%, P<0.05)$. However, other variables were not significantly different among the two groups.

\section{Neonatal outcomes}

We found that pregnant women with symptoms of depression had higher rate of LBW than that of nondepressed women in Table $2(p<0.05)$. However, other adverse birth outcomes did not differ among the two groups.

\section{Depression and risk factors of low birth weight}

Univariate Logistic regression analysis was used to evaluate the association between LBW and antenatal depression symptoms in model 1 . As shown in Table 3, offspring born women with antenatal depression were more likely to be low birth weight than offspring born to women without antenatal depression (odd ratio [OR]2.39,95\% confidence interval [CI]:1.17-4.89). In the model2, after adjusting potential confounders (maternal age, household registration type, high-risk women, passive smoking, primigravida, pre-pregnancy body mass index and male sex), this association was still significant (OR2.05, 95\% CI: 1.12-4.6). Stratified analysis showed a significant association when maternal age $<25$ and temporary residence (Table 4).

\section{Discussion}

In the present study, an association was observed between antenatal depression symptoms and low birth weight. Women with significantly higher EPDS score were more likely to have low birth weight infants. This association persisted after adjusting for confounders, including pre-pregnancy BMI, neonate gender, maternal age, degree of education, high-risk women and parity. Findings in previous studies regarding the association between antenatal depression and low birth weight remain inconclusive. This disparity may result in different sample size, confounders adjusted, and depression symptoms measurements.
In order to facilitate large-scale epidemiological investigation, EPDS was used as the depression symptom measurement. Although clinician administered diagnostic instruments are the gold standard, they are timeconsuming and staff intensive to administer [18]. Conversely, patient-rated screening instruments are easier to use. Because adverse obstetrical outcomes can have significant, long-term, negative health impacts, it would be useful to screen depression at the initial obstetric visit predicts the risk of adverse pregnancy outcomes. EPDS is the only instrument designed to exclude somatic depressive symptoms that are also common symptoms of pregnancy. The effectiveness in antenatal women has been verified by previous studies with excellent reliability [12, 14]. Additionally, a Chinese translation of the EPDS has been demonstrated to have good reliability and validity [15]. We focused on depression symptoms rather than clinically diagnosed depression. The results showed that depression symptoms during pregnancy still had a positive effect on LBW after adjusting several confounders.

Our findings are in keeping with those studies in America black women with large sample size. Some studies [19-21] agreed that depression symptoms are one of the causes of LBW, especially in Neggers's study [19], depression symptoms rather than depression was concerned. Consistent with our results, Negger et al found that women who are depressed during pregnancy are at increased risk of giving birth to low birth weight (AOR $=1.4,95 \%$ CI: 1.1-1.7), in which the measure of depression was conducted by the Center for Epidemiologic Studies Depression Scale (CES-D). Although the depression measure was not the same, we both concerned about the depression symptoms rather than the diagnosis of depressive disorder. However, our attention is paid on the second trimester, suggesting that the depressive stage should be concerned and controlled in earlier pregnancy. Additionally, EPDS is more convenient to use in large population survey. Evans's study used EPDS to screen depression symptoms at 18 and 32 weeks respectively in 13,194 British women, showed that

Table 2 Neonatal outcomes of women with and without antenatal depression

\begin{tabular}{|c|c|c|c|c|c|}
\hline & \multicolumn{2}{|c|}{ Not depressed $($ EPDS $<12)$} & \multicolumn{2}{|c|}{ Depressed (EPDS $\geq 12)$} & \multirow[t]{2}{*}{$P$} \\
\hline & $\%$ & Number & $\%$ & Number & \\
\hline Newborn gender, male & 51.8 & 574 & 57.8 & 155 & 0.074 \\
\hline Preterm birth & 4.2 & 47 & 6.7 & 18 & 0.086 \\
\hline Low birth weight & 2.0 & 22 & 4.5 & 12 & 0.018 \\
\hline Macrosomia $^{a}$ & 5.2 & 58 & 5.6 & 15 & 0.810 \\
\hline Small for gestational age ${ }^{b}$ & 5.2 & 58 & 3.4 & 9 & 0.201 \\
\hline Large for gestational age ${ }^{c}$ & 4.2 & 47 & 4.9 & 13 & 0.659 \\
\hline
\end{tabular}

${ }^{\mathrm{a}}$ Macrosomia was that birth weight was heavier than $4000 \mathrm{~g}$

${ }^{b}$ Small for gestational age (SGA) was that birth weight was lower than the 10th percentile of the average weight of the same gestational age

${ }^{c}$ Large for gestational age (SGA) was that birth weight was greater than the 10th percentile of the average weight of the same gestational age 
Table 3 Odds ratios and $95 \% \mathrm{Cl}$ for the risk of LBW by antenatal depression symptoms

\begin{tabular}{lcclll}
\hline & NBW & & & LBW \\
\cline { 2 - 3 } \cline { 5 - 6 } & Model $^{1}$ & Model $^{2}$ & & Model $^{1}$ & Model $^{2}$ \\
\hline EPDS & 1.00 & 1.00 & & $2.39(1.17,4.89)$ & $2.05(1.12,4.64)$ \\
\hline
\end{tabular}

${ }^{1}$ Model1 was not adjusted

${ }^{2}$ Model 2 was adjusted for pre-pregnancy BMI, neonate gender, maternal age, degree of education, high-risk women and parity

depression symptoms at 18 weeks increased the risk of LBW, but the risk was disappeared after adjusting smoking [22]. It was possible that smoking lies on the causal pathway between depression and intrauterine growth restriction. Adjustment for smoking removed any evidence of a detect association between birth weight and mood during pregnancy. This study mainly focused on white women. We have noticed that the results in different races are conflicting. In a prospective cohort study of 819 African-American women, El-Mohands et al. [20]. Found that women with depression, assessed at $<29$ weeks gestational age, had $71 \%$ increased odds of LBW in adjusted analysis $(\mathrm{OR}=1.71[95 \% \mathrm{CI}=1.12,2.62])$. Another study among 583 women in Bangladesh [23], showed that depression in the 3rd trimester, assessed via the EPDS, doubled the odds of LBW (OR $=2.24$ [95\%CI$1.37,3.68])$ in adjusted analysis. Whether the association

Table 4 Odds ratios (95\%Cl) for depression symptoms on low birth weight stratified by maternal age, residence type, prepregnancy BMI and newborn gender

\begin{tabular}{|c|c|c|}
\hline & Model 1 & Model 2 \\
\hline & OR (95\% Cl) & OR $(95 \% \mathrm{Cl})$ \\
\hline \multicolumn{3}{|l|}{ Maternal age ${ }^{a}$} \\
\hline$<25$ & $4.9(0.4-57.8)$ & $14.5(0.6-327.8)$ \\
\hline$\geq 25$ & $2.1(0.9-4.4)$ & $2.0(0.9-4.4)$ \\
\hline \multicolumn{3}{|l|}{ Residence type ${ }^{b}$} \\
\hline Shenzhen residence & $2.1(0.5-8.0)$ & $2.2(0.6-8.7)$ \\
\hline Temporary residence & $2.3(1.0-5.4)$ & $2.4(1.1-5.6)$ \\
\hline \multicolumn{3}{|l|}{ Pre-pregnancy BMI } \\
\hline$<25$ & $1.9(0.9-4.3)$ & $1.8(0.8-4.3)$ \\
\hline$\geq 25$ & $6.8(1.2-37.4)$ & $2.8(0.1-70.0)$ \\
\hline \multicolumn{3}{|l|}{ Newborn gender ${ }^{d}$} \\
\hline Boy & $3.6(1.4-9.0)$ & $2.0(0.7-6.1)$ \\
\hline Girl & $1.1(0.3-4.1)$ & $1.3(0.3-5.7)$ \\
\hline
\end{tabular}

aodel 2 was not adjusted maternal age and adjusted for pre-pregnancy BMI, neonate gender, degree of education, high-risk women and parity ${ }^{\mathrm{b}}$ Model 2 was not adjusted residence type and adjusted for pre-pregnancy BMI, neonate gender, maternal age, degree of education, high-risk women and parity

${ }^{c}$ Model 2 was not adjusted pre-pregnancy BMI and adjusted for neonate gender, maternal age,degree of education, high-risk women and parity ${ }^{\mathrm{d}}$ Model 2 was not adjusted newborn gender and adjusted for pre-pregnancy $\mathrm{BMI}$, maternal age, degree of education, high-risk women and parity between depression and LBW are affected by race, socioeconomic level remains to be further explored.

Relevant studies from China and with large sample size are limited. Yang's case-control study in Wuhan found that antenatal depression or anxiety was not significantly associated with LBW, but individuals with antenatal depression combined with anxiety were at a higher risk of LBW [24]. However, the self-designed questionnaires, rather than a typical screening scale were used in the study for measuring depressive states. Existing reviews tend to suggest that depression, especially in early pregnancy, may be a risk factor for LBW $[25,26]$. Our study supported this view, but more evidence is needed.

We found that young mothers $(<25$ years of age) seem to be more susceptible to antenatal depression. This might be related to depressive younger pregnant women lacking acknowledgement on pregnant health care. Some studies showed that depression has the tendency to occur in younger pregnant women [27]. We also found that antenatal depression symptoms were more common among temporary residents than permanent residents. This may be related to immigration factors, such as dialect, social isolation, life adaption, unfair opportunities, economic problems or the realization of health care [28].

There are several mechanisms that have been proposed to underlie the association between antenatal depression and neonatal outcomes. A hypothesis has been most extensively investigated which proposed that the hypothalamic-pituitary- adrenocortical axis, which stimulates the release of stress hormones such as cortisol and catecholamines, has a mediation on the association [29]. Study also suggested that the association between self-reported depression and gestational age at birth and fetal growth rate was mediated by antenatal maternal cortisol [30]. Additionally, adverse health behaviors were associated with depression, such as depressed women are more likely to smoke and drink during pregnancy than non-depressed women.

There are limitations in this study. Firstly, depression symptoms were assessed at the second-trimester only, so we probably failed to observe the trend of mood changes throughout the pregnancy. Some women whose depression symptoms occurred at the third-trimester might be misclassified into the non-deprssion group, then the adverse effect of antenatal depression on LBW may be underestimated. Furthermore, data on the history of low birth weight delivery were undocumented. Thus there might be some residual confouders were not adjusted.

\section{Conclusion}

Symptoms of depression in pregnancy significantly increased the risk of low birth weight. More researches on antenatal depression and adverse birth outcomes are needed. 


\section{Abbreviations}

BMl: Body Mass Index; Cl: Confidence interval; EPDS: Edinburgh postnatal depression scale; LBW: Low birth weight; NBW: Normal birth weight; OR: Odd ratio; PTB: Preterm birth; SGA: Small for gestational age

\section{Acknowledgments}

We appreciated the hard work of all the maternal and child health care staff in the District maternal and child health care hospital in Nanshan, Shenzhen, China.And we also thank the obstetric nurses for assistance in obtaining questionnaire from participants.

\section{Authors' contributions}

XD designed the study. XL and RG analyzed the data, and prepared the first draft of manuscript under the guidance of XD. XD guided the manuscript development and substantially revised the paper. $\mathrm{HL}$ and JZ were responsible for project administration. DS and XL recruited subjects. TD and WX provided inputs for the data acquisition and analysis. All authors critically reviewed the manuscript and approved the final version submitted for publication.

\section{Funding}

This study was sponsored by the Shenzhen Science and Technology Program (NO.JCYJ20150402100128583) and Sanming Project of Medicine in Shenzhen(SZSM201803061). The funding bodies were not involved in the design of the study, collection and analysis of data, and publication.

\section{Availability of data and materials}

The datasets used and/or analyzed during the current study are available from the corresponding author on reasonable request.

\section{Ethics approval and consent to participate}

This study was approved by the ethics committee of the Maternal \& Child Healthcare Hospital of Nanshan district in Shenzhen, and all participants provided written informed consent.

\section{Consent for publication}

Not applicable.

\section{Competing interests}

The authors declare that they have no competing interests.

\section{Author details}

${ }^{1}$ Nanshan Maternity \& Child Healthcare Hospital of Shenzhen, Shenzhen,

China. ${ }^{2}$ Sun Yat-Sen University, Guangzhou, China.

\section{Received: 13 July 2019 Accepted: 25 February 2020}

Published online: 06 March 2020

\section{References}

1. Organization WH. The global burden of disease: 2004 update. http://www. who.int/healthinfo/global_burden_disease/GBD_report_2004update_full.pdf 2004.

2. Fadzil A, Balakrishnan K, Razali R, Sidi H, Malapan T, Japaraj RP, Midin M, Nik Jaafar NR, Das S, Manaf MRA. Risk factors for depression and anxiety among pregnant women in hospital Tuanku Bainun, Ipoh, Malaysia. Asia Pac Psychiatry. 2013;5(S1):7-13

3. Kim DR, Sockol LE, Sammel MD, Kelly C, Moseley M, Epperson CN. Elevated risk of adverse obstetric outcomes in pregnant women with depression. Arch Womens Ment Health. 2013;16(6):475-82.

4. Gavin NI, Gaynes BN, Lohr KN, Meltzer-Brody S, Gartlehner G, Swinson T. Perinatal depression: a systematic review of prevalence and incidence. Obstet Gynecol. 2005:106(5 Pt 1):1071-83.

5. Parsons CE, Young KS, Rochat TJ, Kringelbach ML, Stein A. Postnatal depression and its effects on child development: a review of evidence from low- and middle-income countries. Brit Med Bull. 2012;101(1):57-79.

6. Ko JY, Farr SL, Dietz PM, Robbins CL. Depression and treatment among U.S. pregnant and nonpregnant women of reproductive age, 2005-2009. J Womens Health. 2012;21(8):830-6.

7. Van den Bergh BRH, Mulder EJH, Mennes M, Glover V. Antenatal maternal anxiety and stress and the neurobehavioural development of the fetus and child: links and possible mechanisms. A review. Neurosci Biobehav Rev. 2005:29(2):237-58.

8. Talge NM, Neal C, Glover V. Antenatal maternal stress and long-term effects on child neurodevelopment: how and why? J Child Psychol Psyc. 2007; 48(3-4):245-61.

9. Valero De Bernabé J, Soriano T, Albaladejo R, Juarranz M, Calle ME, Martinez D, Dominguez-Rojas V. Risk factors for low birth weight: a review [J]. Eur J Obstet Gyn R B. 2004;116(1):3-15.

10. Grote NK, Bridge JA, Gavin AR, Melville JL, lyengar S, Katon WJ. A metaanalysis of depression during pregnancy and the risk of preterm birth, low birth weight, and intrauterine growth restriction. Arch Gen Psychiatry. 2010; 67(10):1012

11. Wang J, Zeng Y, Ni Z, Wang G, Liu S, Li C, Yu C, Wang Q, Nie S. Risk factors for low birth weight and preterm birth: a population-based case-control study in Wuhan, China. J Huazhong Univ Sci Technolog Med Sci. 2017;37(2): 286-92.

12. Alvarado-Esquivel C, Sifuentes-Alvarez A, Salas-Martinez C. Detection of mental disorders other than depression with the Edinburgh postnatal depression scale in a sample of pregnant women in northern Mexico. Ment IIIn. 2016;8(1):6021.

13. Cox JL, Holden JM, Sagovsky R. Detection of postnatal depression Development of the 10-item Edinburgh postnatal depression scale. $\mathrm{Br} J$ Psychiatry. 1987;150:782-6.

14. Gibson J, McKenzie-McHarg K, Shakespeare J, Price J, Gray R. A systematic review of studies validating the Edinburgh postnatal depression scale in antepartum and postpartum women. Acta Psychiat Scand. 2009;1 19(5):350-64.

15. Wang Y, Guo X, Lau Y, Chan KS, Yin L, Chen J. Psychometric evaluation of the mainland Chinese version of the Edinburgh postnatal depression scale. Int J Nurs Stud. 2009;46(6):813-23.

16. Navaratne FK. Impact of a high Edinburgh postnatal depression scale score on obestric and prenatal outcomes. Sci Rep UK. 2016;6:33544.

17. Saenger $P$, Czernichow $P$, Hughes I, Reiter EO. Small for gestational age: short stature and beyond. Endocr Rev. 2007;28(2):219-51.

18. Rita Suri LAGH. Effects of antenatal depression and antidepressant treatment on gestational age at birth and risk of preterm birth. Am J Psychiatry. 2007:164:1206-13.

19. Neggers $Y$, Goldenberg R, Cliver S, Hauth J. The relationship between psychosocial profile, health practices, and pregnancy outcomes. Acta Obstet Gynecol Scand. 2006;85(3):277-85.

20. El-Mohandes AA, Kiely M, Gantz MG, El-Khorazaty MN. Very preterm birth is reduced in women receiving an integrated behavioral intervention: a randomized controlled trial. Matern Child Health J. 2011;15(1):19-28.

21. Kiely M, El-Mohandes AA, Gantz MG, Chowdhury D, Thornberry JS, ElKhorazaty MN. Understanding the association of biomedical, psychosocial and behavioral risks with adverse pregnancy outcomes among AfricanAmericans in Washington, DC. Matern Child Health J. 2011;15(Suppl 1):S8595.

22. Evans J, Heron J, Wiles N. Depressive symptoms during pregnancy and low birth weight at term: longitudinal study. Br J Psychiatry. 2007;191:84-5.

23. Nasreen HE, Kabir ZN, Forsell Y, Edhborg M. Low birth weight in offspring of women with depressive and anxiety symptoms during pregnancy: results from a population based study in Bangladesh. BMC Public Health. 2010;10: 515.

24. Yang S, Yang R, Liang S, Wang J, Weaver NL, Hu K, Hu R, Trevathan E, Huang $Z$, Zhang $Y$, et al. Symptoms of anxiety and depression during pregnancy and their association with low birth weight in Chinese women: a nested case control study. Arch Womens Ment Health. 2017;20(2):283-90.

25. Szegda K, Markenson G, Bertone-Johnson ER, Chasan-Taber L. Depression during pregnancy: a risk factor for adverse neonatal outcomes? A critical review of the literature. J Matern Fetal Neonatal Med. 2013;27(9):960-7.

26. Accortt EE, Cheadle ACD, Dunkel Schetter C. Prenatal depression and adverse birth outcomes: an updated systematic review. Matern Child HIth J. 2015;19(6):1306-37.

27. Klainin P, Arthur DG. Postpartum depression in Asian cultures: a literature review. Int J Nurs Stud. 2009;46(10):1355-73.

28. Gagnon AJ, Zimbeck M, Zeitlin J, Alexander S, Blondel B, Buitendijk S, Desmeules M, Di Lallo D, Gagnon A, Gissler M, et al. Migration to western industrialised countries and perinatal health: a systematic review. Soc Sci Med. 2009;69(6):934-46.

29. Giurgescu C. Are maternal cortisol levels related to preterm birth? J Obstet Gynecol Neonatal Nurs. 2009:38(4):377-90. 
30. Sandman CA, Wadhwa PD, Chicz-DeMet A, Dunkel-Schetter C, Porto M. Maternal stress, HPA activity, and fetal/infant outcome. Ann N Y Acad Sci. 1997;814:266-75

\section{Publisher's Note}

Springer Nature remains neutral with regard to jurisdictional claims in published maps and institutional affiliations.

Ready to submit your research? Choose BMC and benefit from:

- fast, convenient online submission

- thorough peer review by experienced researchers in your field

- rapid publication on acceptance

- support for research data, including large and complex data types

- gold Open Access which fosters wider collaboration and increased citations

- maximum visibility for your research: over $100 \mathrm{M}$ website views per year

At BMC, research is always in progress. 